Made available courtesy of Botanical Society of America: http://www.botany.org/

***Reprinted with permission. No further reproduction is authorized without written permission from the Botanical Society of America. This version of the document is not the version of record. Figures and/or pictures may be missing from this format of the document.***

American Journal of Botany 81(3): 278-286. 1994.

\title{
Carbon integration in Plantago aristata (Plantaginaceae): the reproductive EFFECTS OF DEFOLIATION ${ }^{1}$
}

\author{
MARgaret Horton and Elizabeth P. LACEY ${ }^{2}$ \\ Department of Biology, 312 Eberhart Building, University of North Carolina, \\ Greensboro, North Carolina 27412
}

\begin{abstract}
Patterns of carbon integration in aclonal species are poorly understood in spite of their potential to influence individual fitness. To provide more information about these patterns, we performed a defoliation experiment with $P$. aristata. We examined, at the metameric level, the reproductive responses to the removal of the major carbon sources within metamers. Bracts on marked reproductive spikes and leaves subtending these spikes were removed at three stages of reproductive maturity: spike elongation, flowering, and fruiting. Spike dry weight and length, capsule number, seeds per capsule, and seed weight were measured. We tested the hypothesis that seed weight would respond least to defoliation. We also performed a complementary ${ }^{14} \mathrm{C}$ translocation experiment to measure the amount of radioactive carbon moving into the marked spikes from outside the metamer. Defoliation depressed all components of reproduction within marked spikes, and little ${ }^{14} \mathrm{C}$ was translocated from outside the metamer into the reproductive spikes, even those that were defoliated. Both results support the view that reproductive metamers in this species are largely autonomous with respect to their carbon budget. Defoliation during spike elongation most depressed reproduction, and bract removal depressed reproduction more than did leaf removal. The data suggest that bracts compensate for leaf removal by increasing their photosynthetic rate; however, the ability to compensate differs among plant populations. Of all the reproductive components, seed weight was least affected by defoliation. The data show, however, that the time of defoliation relative to reproductive development influences which reproductive components are affected.
\end{abstract}

Ecological and evolutionary interest in the physiological integration of plants has blossomed in the last few decades. This interest has been motivated by the desire to understand how such integration affects a genotype's ability to persist in a particular environment. Interest in physiological integration prompted Watson and Casper (1984) to coin the term integrated physiological unit (IPU) to emphasize the fact that the functional unit of organization in a plant conceptually differs from the morphological units of organization. Within an IPU the assimilation, distribution, and utilization of a resource, like carbon, is regulated. The IPU boundaries within a plant may coincide loosely with any one of the morphological units constituting a plant, e.g., metamer, branch, ramet, and usually change as a plant develops (see reviews by Watson and Casper, 1984; Watson, 1986).

Much of the empirical research on IPUs has focused on identifying the boundaries of the IPU for carbon in different plant species. Biologists have measured carbon translocation among ramets within clonal plant species (e.g., see reviews by Pitelka and Ashmun, 1985; Hutchings and Bradbury, 1986; Marshall, 1990; Schmid, 1990; more recently: Chapman, Robson, and Snaydon, 1992; Landa et al., 1992). A few have also examined carbon translocation among branches and metamers in aclonal species (Janzen, 1976; Stephenson, 1980; Bertin, 1982; Marquis,

${ }^{1}$ Received for publication 28 June 1993; revision accepted 12 October 1993.

The authors thank K. Landa, C. Marshall, and M. Watson for helpful comments on a previous draft of this paper; $M$. Watson for use of laboratory and greenhouse facilities to gather the ${ }^{14} \mathrm{C}$ translocation data; K. Landa and T. Preuninger for help collecting data; and D. Herr for statistical advice. This study was partially supported by a Sigma Xi grant-in-aid to $\mathrm{MH}$.

${ }^{2}$ Author for correspondence.
1988; Thomas and Watson, 1988; Garrish and Lee, 1989; Tuomi et al., 1989; Kemball, Palmer, and Marshall, 1992; Lacey and Marshall, 1992). Translocation has been measured both in stressed and unstressed plants and at different developmental stages. These studies provide information about the degree of integration of different morphological units, i.e., the IPU boundaries, in a variety of environmental conditions.

Fewer empirical studies have examined the relationship between the IPU and fitness. Patterns of carbon integration have the potential to influence lifetime reproductive output, which contributes strongly to fitness. A few biologists have performed defoliation experiments in aclonal species to examine the reproductive responses of removing carbon sources or sinks (Janzen, 1976; Stephenson, 1980; Marquis, 1988; Thomas and Watson, 1988; Garrish and Lee, 1989; Marshall, 1989; Shea and Watson, 1989; Tuomi et al., 1989). However, because most of the defoliation experiments have been used to measure the degree of integration among morphological units, i.e., used to identify IPU boundaries, information about the relationship between the IPU and fitness is limited. Ideally, one would like a priori knowledge of the IPU boundaries. Then after defoliation, one could observe the reproductive response, not just at the whole plant level but also at the level of the IPU.

We conducted such a defoliation experiment using Plantago aristata, bracted plantain. $P$. aristata is an annual rosette species that produces reproductive spikes from the axils of mature leaves. Subtending each flower on a spike is a green bract. In an unstressed plant of this species, very little carbon is translocated between reproductive metamers, a metamer being operationally defined as a spike and its subtending leaf (Lacey and Marshall, 1992). Based on this observation, we made the a priori 
assumption that a reproductive metamer is an IPU for carbon in $P$. aristata. Then we asked 1) what would be a metamer's reproductive response to removal of its two major carbon sources, leaf and bracts, separately and together and 2) how would the response change with developmental maturity of the spike? Because the degree of reintegration of the defoliated metamer with carbon sources in other metamers could influence the response, we also conducted a ${ }^{14} \mathrm{C}$ translocation experiment to measure the amount of reintegration. Because neither author has observed much herbivory of $P$. aristata in the field, our experiment was performed not to mimic herbivory but rather to learn more about carbon allocation patterns in the species.

Reproduction can be divided into a number of components, e.g., inflorescence number, fruit number per inflorescence, seed number per fruit, and seed size (Adams, 1967; Primack, 1978). All or some of these components can theoretically be altered by defoliation. Harper, Lovell, and Moore (1970) proposed that seed size is the most conservative reproductive component, responding least to stress, because seed size strongly influences individual fitness. Others (e.g., Lloyd, 1980; Stephenson, 1981; Bookman, 1983) proposed that fruit number responds greatly to stress. Previous studies (e.g., Harper, Lovell, and Moore, 1970; Stephenson, 1984; Marshall, Levin, and Fowler, 1986; Agren, 1989; Marshall, 1989) have tested the hypothesis that stress negatively affects fruit number more than it does seed size at the whole-plant level, and most provide supporting evidence for the hypothesis. In the experiment described below, we tested this hypothesis at the level of the metamer. Lee and Bazzaz (1980) proposed that the time of the stress relative to reproductive development should influence which reproductive components are affected by the stress. Therefore, we also tested the hypothesis that the negative effect of defoliation on seed size would be manifested later in spike development than would the negative effect on fruit number.

\section{MATERIALS AND METHODS}

Study species - Plantago aristata Michx. (Plantaginaceae), bracted plaintain, is an acaulescent winter annual that is native to the southeastern United States. Unlike many annuals that grow vegetatively as a rosette, $P$. aristata retains its rosette form throughout its life. The reproductive spikes arise from the axils of fully expanded leaves. Each spike bears numerous sessile cleistogamous flowers, and each flower is subtended by a conspicuous green bract. Flowers develop into two-seeded capsules (Johnson, 1981).

Defoliation experiment - We collected seeds for our experiments from two populations approximately $4 \mathrm{~km}$ apart in Guilford County, North Carolina. Seeds were stored separately by maternal family in paper bags in the laboratory for approximately $6 \mathrm{mo}$. Then we sowed seeds from a haphazardly selected sample of families, by family, into Terralite potting soil in small pots. After the first leaves appeared, we transplanted seedlings individually into pots (approximately $7 \mathrm{~cm}$ diam) and randomly assigned each plant a position in a growth chamber. The few seedlings that died during the first wk in the growth chamber were replaced with seedlings from the original germination pots. Of the 360 plants transplanted, excluding replacements, 341 survived to harvest.

During germination, the plants grew under $12-\mathrm{hr} \mathrm{d}$ at approximately $22 \mathrm{C}$. For the first $7 \mathrm{wk}$ after transplanting, the plants experienced "winter" conditions: $8 \mathrm{hr}$ light at $19 \mathrm{C} / 16 \mathrm{hr}$ dark at $13 \mathrm{C}$. They were watered three times per wk and fertilized once per wk with $1 / 4$-strength Hoagland's solution. At the end of $7 \mathrm{wk}$, we reprogrammed the growth chamber for "summer" conditions: $14 \mathrm{hr}$ light at $26 \mathrm{C} / 10 \mathrm{hr}$ dark at $20 \mathrm{C}$. We watered the plants four times and fertilized them twice in an 8-d cycle until senescence began, which was approximately 17 wk after transplanting. At that time we reduced the watering to three times and fertilization to once in the 8-d cycle.

At the time of transplanting, we randomly assigned three seedlings from each of six families per population to one of ten treatments: nine experimental treatments and one control group. Each experimental treatment was characterized by the removal of some combination of photosynthetic source organs from a marked metamer at a particular developmental stage of the metamer's reproductive spike. We performed three different types of removals. With scissors we clipped either the bracts on the reproductive spike, or the leaf subtending the spike, or both the bracts and leaf. The cuts were made as close to the bottom of the target organs as possible. We clipped the experimental plants at one of three developmental stages: during spike elongation, when the spike was 1-3 $\mathrm{cm}$ long; during flowering, just after the first flower of the inflorescence had opened; and during fruiting, after all the flowers on the spike had opened. During spike elongation, the inflorescence develops, and bracts on the inflorescence continue to grow. Therefore, we retrimmed the bracts an additional zero to five times, as necessary. In contrast to the bracts, subtending leaves were fully expanded at the time of initial clipping. No leaves or bracts were removed from the plants in the control group.

Reproductive spikes first appeared 12 wk after transplanting. The first metamer to produce a spike on each plant was tagged and used as either an experimental or control metamer. When the spike in the tagged metamer turned brown, we harvested the plant. We dried and weighed each marked spike, without its bracts and subtending leaf. We also weighed the remaining portions of the shoot, which we collected and dried separately. All plant parts were oven dried at approximately $65 \mathrm{C}$ for $2 \mathrm{~d}$.

Data for several components of reproduction were collected from each marked metamer: spike dry weight, spike length, and capsule number. We measured spike biomass, because, despite its shortcomings, biomass is most commonly used to measure the resources a plant allocates to reproduction (e.g., Bazzaz and Reekie, 1985; Marshall and Watson, 1992). We measured spike length because spike elongation in P. aristata continues during flowering and fruiting. If carbon resources available to the metamer are limited, a reduction in spike length might occur, especially if carbon was limited early in spike development when elongation is most rapid.

For a subset of treatments (i.e., all defoliation treatments during spike elongation, bract and leaf removal 
TABLE 1. Mean square (MS) values for analyses of variance and ANOVA contrasts for reproductive components in Plantago aristata. Main sources of variation were treatments $(\mathrm{T})$, which corresponded to the defoliation by development stage combinations, populations $(\mathrm{P})$, and families $(\mathrm{F})$ nested within population. Shoot dry weight (S) was included as a covariate. The defoliation treatments included bract and leaf removal (B\&L), bract removal (B), and leaf removal (L); the development stages were spike elongation (E), flowering $(\mathrm{Fl})$, and fruiting $(\mathrm{Fr})$. $\mathrm{C}=\mathrm{control}$. Contrasts were averaged over families. ${ }^{\mathrm{a}}$

\begin{tabular}{|c|c|c|c|c|c|}
\hline Source & df & $\begin{array}{l}\text { Spike dry weight } \\
\text { MS }\end{array}$ & $\begin{array}{l}\text { Spike length } \\
\text { MS }\end{array}$ & $\begin{array}{l}\text { Capsule no. } \\
\text { MS }\end{array}$ & $\begin{array}{c}\text { Total plant spike dry weight } \\
\text { MS }\end{array}$ \\
\hline Full model & 120 & $16,047^{* * * *}$ & $2,269 * * * *$ & $378^{* * * *}$ & $1.04 * * * *$ \\
\hline $\mathrm{T}$ & 9 & $101,174 * * * *$ & $15,621^{* * * *}$ & $2,593^{* * * *}$ & $0.056^{\mathrm{ns}}$ \\
\hline $\mathbf{P}$ & 1 & $419,284 * * * *$ & $39,063^{* * * *}$ & $5,184^{* * * * *}$ & $3.361^{* * * * *}$ \\
\hline$T * P$ & 9 & $7,882 *$ & $1,132^{\mathrm{ns}}$ & $281^{* *}$ & $0.060^{\mathrm{ns}}$ \\
\hline $\mathrm{F}(\mathrm{P})$ & 10 & $15,088^{* * * *}$ & $2,458^{* * *}$ & $386^{* * * * *}$ & $0.577^{* * *}$ \\
\hline$T * F(P)$ & 90 & $3,666^{\text {ns }}$ & $5,894^{\mathrm{ns}}$ & $114^{\mathrm{ns}}$ & $0.050^{\mathrm{ns}}$ \\
\hline S & 1 & $1,581^{\mathrm{ns}}$ & $871^{\text {ns }}$ & $98^{\text {ns }}$ & $40.113^{* * * *}$ \\
\hline Error & 217 & 3,183 & 698 & 95 & 0.043 \\
\hline \multicolumn{6}{|l|}{ Contrasts } \\
\hline E vs. Fl & 1 & $260,412^{* * * *}$ & $53,208^{* * * *}$ & $6,923^{* * * *}$ & \\
\hline Fl vs. Fr & 1 & $18,990^{*}$ & $458^{\mathrm{ns}}$ & $217^{\mathrm{ns}}$ & \\
\hline Fr vs. C & 1 & $7,779^{\text {ns }}$ & $567^{\mathrm{ns}}$ & $11^{\mathrm{ns}}$ & \\
\hline B\&L vs. $C$ & 1 & $183,976^{* * * *}$ & $15,973 * * * *$ & $3,055^{* * * *}$ & \\
\hline B vs. C & 1 & $93,219^{* * * *}$ & $11,875^{* * * *}$ & $1,073^{* *}$ & \\
\hline L vs. C & 1 & $9,441^{\text {ns }}$ & $1,189^{\mathrm{ns}}$ & $11^{\mathrm{ns}}$ & \\
\hline B\&L vs. B & 1 & $30,555^{* *}$ & $583^{\text {ns }}$ & $1,002^{* *}$ & \\
\hline
\end{tabular}

during flowering and fruiting, and the control group), we also determined the mean number of seeds per capsule and mean seed weight per spike. Mean seed number per capsule was determined by counting the mature seeds on each spike and dividing by capsule number for that spike. To determine mean seed weight per spike, we divided total seed weight by seed number for each spike. Finally, to examine the effect of the treatments on the reproductive output of the rest of the plant, we weighed all the reproductive spikes on the plant, excluding the marked spike.

The data were examined with analyses of variance (SAS Institute, 1985) to evaluate the effects of treatment, population, family nested within population, and their interactions on each reproductive trait. We included total shoot biomass as a covariate in each model to adjust for individual differences in plant size. We used the Contrasts option to examine the specific effects of treatment with regard to both the developmental stage at removal and the source organs removed. Three plants were excluded from the analyses because the value of one of their reproductive traits differed from the treatment group mean by more than three standard deviations. Because we found no evidence prior to the analyses that the data were not normally distributed, we did not transform the data.

Translocation experiment-We germinated a second sample of seeds from the same populations, but different families, under conditions described in the defoliation experiment. After 4 wk we transplanted seedlings individually into pots and randomly assigned the pots to the remaining spaces in the growth chamber, where they experienced "summer" conditions. We watered the plants four times and fertilized them twice every $8 \mathrm{~d}$ for the next $6 \mathrm{wk}$. At that time we reduced the watering and fertilization to three times and once, respectively, per 8-d cycle. Three months after transplanting, we transported the flowering plants to Bloomington, Indiana for the tracer study. The plants were placed in a greenhouse (14 hr light, 24-40 C) and allowed to acclimate for $48 \mathrm{hr}$.
We then established four treatment groups, each containing three plants. First we placed plants into two categories based upon the presence of a spike in either the elongation or flowering developmental stage. The elongating or flowering spike was marked. Then within these two developmental categories, we randomly designated individuals as either experimentals or controls. Prior to ${ }^{14} \mathrm{CO}_{2}$ exposure, we removed the bracts and subtending leaf on the marked metamer of the experimentals. No removals were made on the controls.

Twenty-three hours after the removal of source organs, we placed all of the shoot except the marked metamer in an acetate chamber (one plant per chamber) and exposed the shoot to $5 \mathrm{ml}$ of $2 \mathrm{mCi}$ of ${ }^{14} \mathrm{CO}_{2}$. The chambers were removed after $30 \mathrm{~min}$, and the plants were left in the greenhouse for $26 \mathrm{hr}$, at which time they were harvested. We separated the exposed portion of the shoot, the roots, and the unexposed spike and dried them at $65 \mathrm{C}$ for approximately $72 \mathrm{hr}$. For the control plants, we removed the bracts and subtending leaf from the spike and dried each part separately.

Then we measured the amount of radioactive carbon in each part of three replicate plants per treatment. Plant parts were weighed and ground prior to combustion in oxygen. We oxidized two $20-\mathrm{mg}$ samples from each shoot and from each root system, and one 20-mg sample from each unexposed spike. For the control plants, we also oxidized a 20-mg sample from the bracts and from the subtending leaf on the unexposed metamer. When the flowering spike, bracts, or leaf weighed less than $20 \mathrm{mg}$, we oxidized the entire part. Each sample was combusted at $900 \mathrm{C}$ using a RJ Harvey Instrument Corporation Biological Oxidizer $0 \mathrm{X} 400$. The liberated ${ }^{14} \mathrm{CO}_{2}$ was collected in separate scintillation vials containing $\mathrm{C} 14$ cocktail (Harvey Instrument Corp., Hillsdale, NJ) and counted with a Beckman LS-230 liquid scintillation counter. These methods closely followed those described by Landa et al. (1992). We used the counts, along with the mass of the sample combusted and the total mass of the plant part, 
to compute the percentage of the total ${ }^{14} \mathrm{CO}_{2}$ uptake of the plant imported by each unexposed spike. To compare the experimental and control spikes, we used the biomass and cpm of the control spike minus its bracts. Analysis of variance was used to determine if developmental stage and defoliation influenced assimilate movement into the marked spike.

\section{RESULTS}

Defoliation experiment-Treatment significantly affected all aspects of reproduction in the marked metamer per plant: spike length and dry weight, capsule number, seeds per capsule, and seed weight (Tables 1, 2). However, it did not affect the dry weight of all other reproductive structures on the experimental plants.

Defoliation reduced reproductive output of the metamer, but the negative effect was restricted almost entirely to the earliest developmental stage (Fig. 1). Only seed weight was affected by defoliation during flowering or fruiting. All reproductive components were negatively affected by defoliation during spike elongation. Spike dry weight and capsule number were reduced by approximately $30 \%$ from those of the controls when averaged over all combinations of bract and leaf removal. The contrasts (Tables 1,2 ) show significant differences in reproductive responses to defoliation made during spike elongation and those made during flowering, even when one takes into account the number of multiple contrasts performed. By flowering time the defoliation effects disappeared.

The different components of reproduction showed two major patterns of response to defoliation (Fig. 1). First, the components quantitatively differed in their response. Spike dry weight and capsule number were reduced the most by defoliation during spike elongation $(33 \%$ and $27 \%$ reduction, respectively, when averaged over all combinations of bract and leaf removal). Spike length was reduced by $22 \%$. Seeds per capsule and seed weight were reduced the least, by only $7 \%$ and $5 \%$, respectively. Second, the reproductive components differed in the persistence of their response. Mean seed weight per spike was reduced by defoliation during flowering as much as it was by defoliation during spike elongation (see contrasts, Table 1). Only after flowering had begun did the defoliation effect begin to disappear. In contrast, none of the other reproductive components showed any negative effect of defoliation beyond the spike elongation phase.

Removing different combinations of carbon sources within a metamer strongly influenced the reproductive response (Fig. 1). Removing the subtending leaf, alone, did not affect any reproductive component when compared to the control group. In contrast, bract and leaf removal, as well as removal of bracts alone, depressed all of the reproductive components. These reductions were highly significant when compared to reproduction in the control group (contrasts, Tables 1,2). Bract and leaf removal produced a significantly greater negative response in spike dry weight, capsule number, and seeds per capsule than did bract removal alone (see contrasts, Tables 1, 2). We observed the largest reduction in spike dry weight and capsule number, which were reduced by approximately
TABLE 2. Mean square (MS) values for analyses of variance and ANOVA contrasts for reproductive components in $P$. aristata $^{\text {a }}$

\begin{tabular}{|c|c|c|c|c|}
\hline \multirow[b]{2}{*}{ Source } & \multicolumn{2}{|c|}{ Seeds per capsule } & \multicolumn{2}{|c|}{ Mean seed weight } \\
\hline & df & MS & df & MS \\
\hline Full model & 72 & $0.160^{* * * * *}$ & 71 & $0.091^{* * * *}$ \\
\hline $\mathrm{T}$ & 5 & $0.638^{* * * *}$ & 5 & $0.185^{* * * *}$ \\
\hline $\mathbf{P}$ & 1 & $1.107^{* * * * *}$ & 1 & $0.362^{* * *}$ \\
\hline$T * P$ & 5 & $0.659^{* * * * *}$ & 5 & $0.021^{\mathrm{ns}}$ \\
\hline $\mathrm{F}(\mathrm{P})$ & 10 & $0.145^{* *}$ & 10 & $0.183^{* * * *}$ \\
\hline $\mathrm{T} * \mathrm{~F}(\mathrm{P})$ & 50 & $0.075^{*}$ & 49 & $0.033^{\mathrm{ns}}$ \\
\hline S & 1 & $0.028^{\mathrm{ns}}$ & 1 & $0.316^{* * *}$ \\
\hline Error & 122 & 0.047 & 121 & 0.0256 \\
\hline \multicolumn{5}{|l|}{ Contrasts } \\
\hline E vs. Fl & 1 & $1.79 * * * *$ & 1 & $0.0003^{\mathrm{ns}}$ \\
\hline Fl vs. Fr & 1 & $0.001^{\mathrm{ns}}$ & 1 & $0.171^{*}$ \\
\hline Fr vs. C & 1 & $0.001^{\text {ns }}$ & 1 & $0.102^{\mathrm{ns}}$ \\
\hline B\&L vs. C & 1 & $1.770^{* * * *}$ & 1 & $0.487^{* * *}$ \\
\hline B vs. C & 1 & $0.144^{\text {ns }}$ & 1 & $0.490^{* * *}$ \\
\hline L vs. C & 1 & $0.0005^{\mathrm{ns}}$ & 1 & $0.103^{\mathrm{ns}}$ \\
\hline
\end{tabular}

$50 \%$ when bracts and leaf were removed during spike elongation.

The two populations and the families within populations significantly differed in all reproductive components measured (Tables 1,2). Additionally, the treatment by population interactions were often significant. The effects of removing different combinations of carbon sources as manifested in spike dry weight, capsule number, and seeds per capsule differed for the two populations (Fig. 2). In one population, removing the bracts and subtending leaf substantially depressed spike dry weight, capsule number, and seeds per capsule from that observed when only bracts were removed. In the other population, bract and leaf removal and bract removal, alone, produced similar responses.

Translocation experiment - The ${ }^{14} \mathrm{C}$ measurements showed that the marked spikes did receive carbon from sources outside the spike's metamer. However, the amount totaled less than $1.5 \%$, even for those plants that had their carbon sources removed. The percent imported into defoliated and control spikes during spike elongation was $1.189 \pm 0.082$ and $1.276 \pm 0.815$ (mean + S.E.), respectively. The percent imported into defoliated and control spikes during flowering was $1.247 \pm 0.455$ and 0.349 \pm 0.166 , respectively.

Spike size increased dramatically from time of elongation to flowering. Mean spike dry weights for defoliated and control spikes at elongation were 20.7 and $22.6 \mathrm{mg}$, respectively; spike weights at flowering were 119.4 and $93.9 \mathrm{mg}$, respectively. When the percent ${ }^{14} \mathrm{C}$ imported into the spike was standardized for spike size, less than $0.1 \%$ per $\mathrm{mg}$ was detected in the spike.

The analysis of variance detected no significant effects of defoliation or developmental stage on the percent of ${ }^{14} \mathrm{C}$ imported into the marked spikes (Table 3). On a permg spike basis, however, developmental stage did significantly influence the amount imported. There was a six- to tenfold drop in percent imported per mg spike from spike elongation to flowering. Thus, it appears that while the total amount of translocated carbon into the 

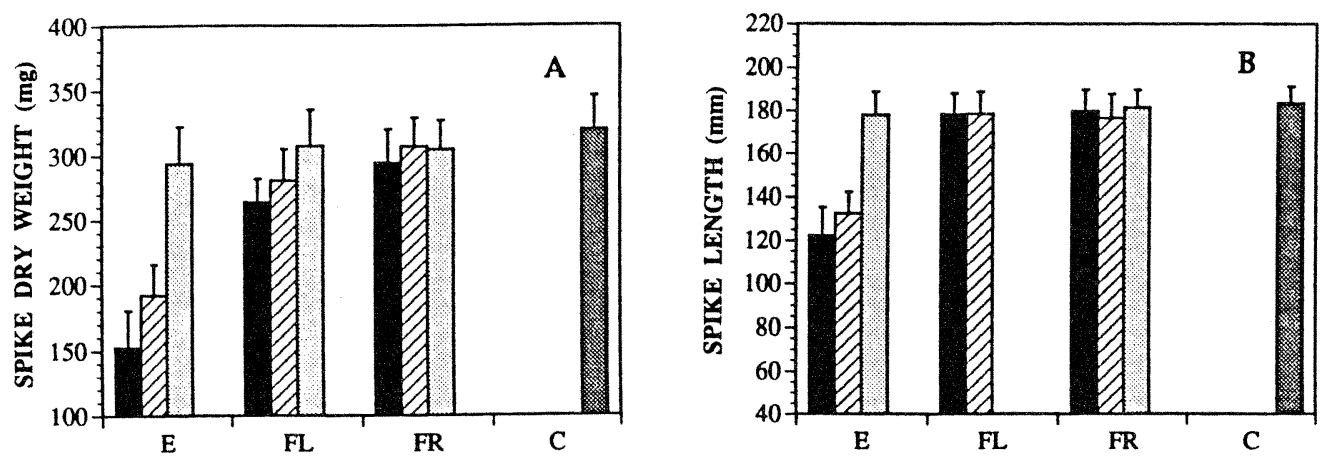

PARTS REMOVED
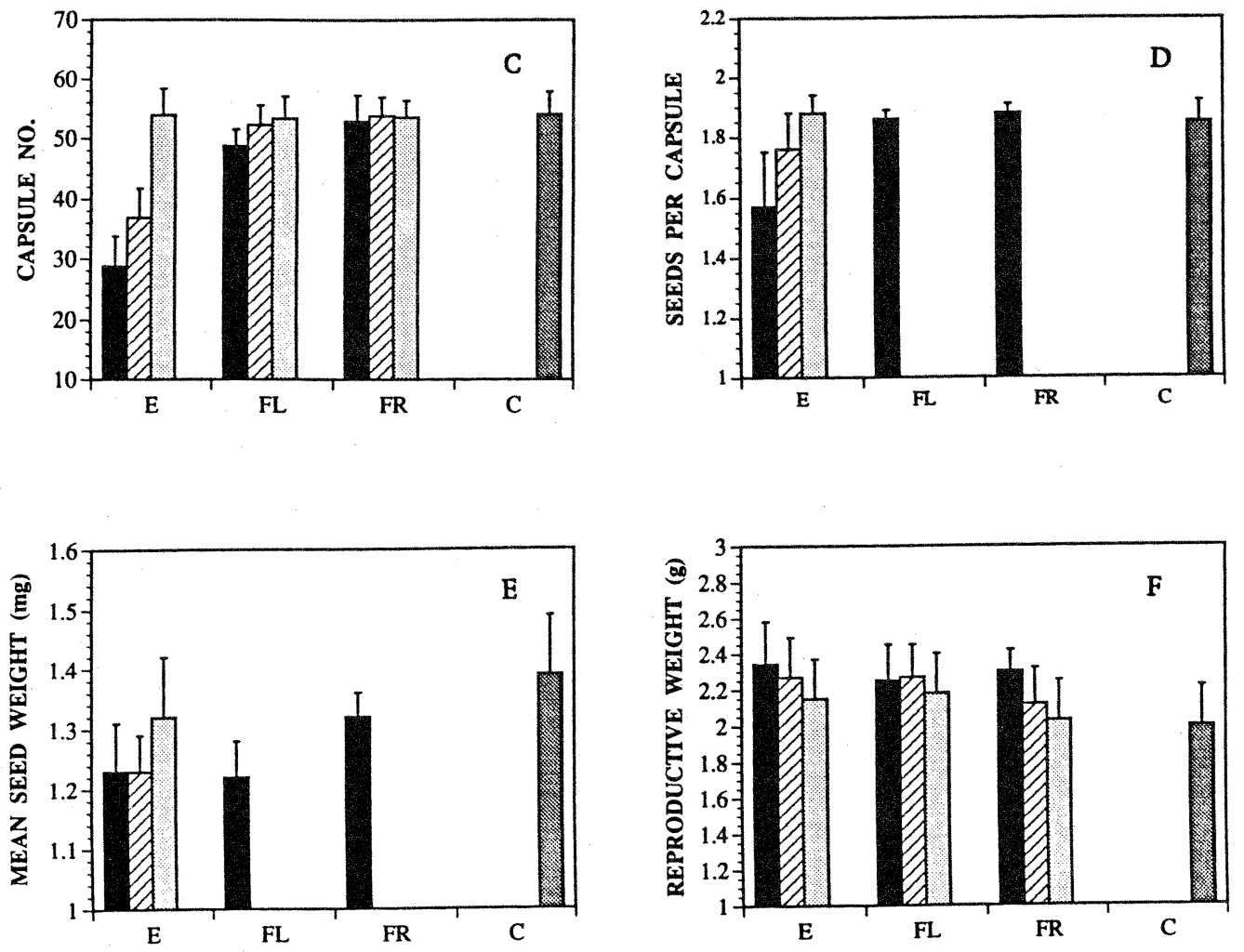

DEVELOPMENTAL STAGE

Fig. 1. Reproductive responses to defoliation at different developmental stages in Plantago aristata expressed in terms of mean \pm 2 SE for both populations combined. Graphs A-E refer to the response of the marked metamer in terms of: A) dry weight of the reproductive spike, B) spike length, C) capsule number, D) seeds per capsule, E) seed weight. Graph F shows the dry weight of all reproductive spikes per plant, not including the spike on the marked metamer. Developmental stages at time of removal: spike elongation (E), flowering (Fl), fruiting (Fr). No removals were made on the controls (C). $N=33-36$.

spike remains fairly constant, the translocated carbon is being spread over a greater volume as spike biomass increases.

\section{DISCUSSION}

There are two assumptions that underlie most studies of plant growth and development: first that resources are limited, and second that extant patterns of resource al- location to various structures in a plant reflect past selection for patterns that maximize fitness. These two assumptions suggest that if carbon sources in a reproductive metamer are removed, the plant will reallocate more of its remaining resources to reproductive components that contribute the most to fitness and less to components that contribute least to fitness. There is, at best, weak evidence to support this prediction in $P$. aristata. In $P$. aristata, traits like capsule number, seeds per capsule, and seed 

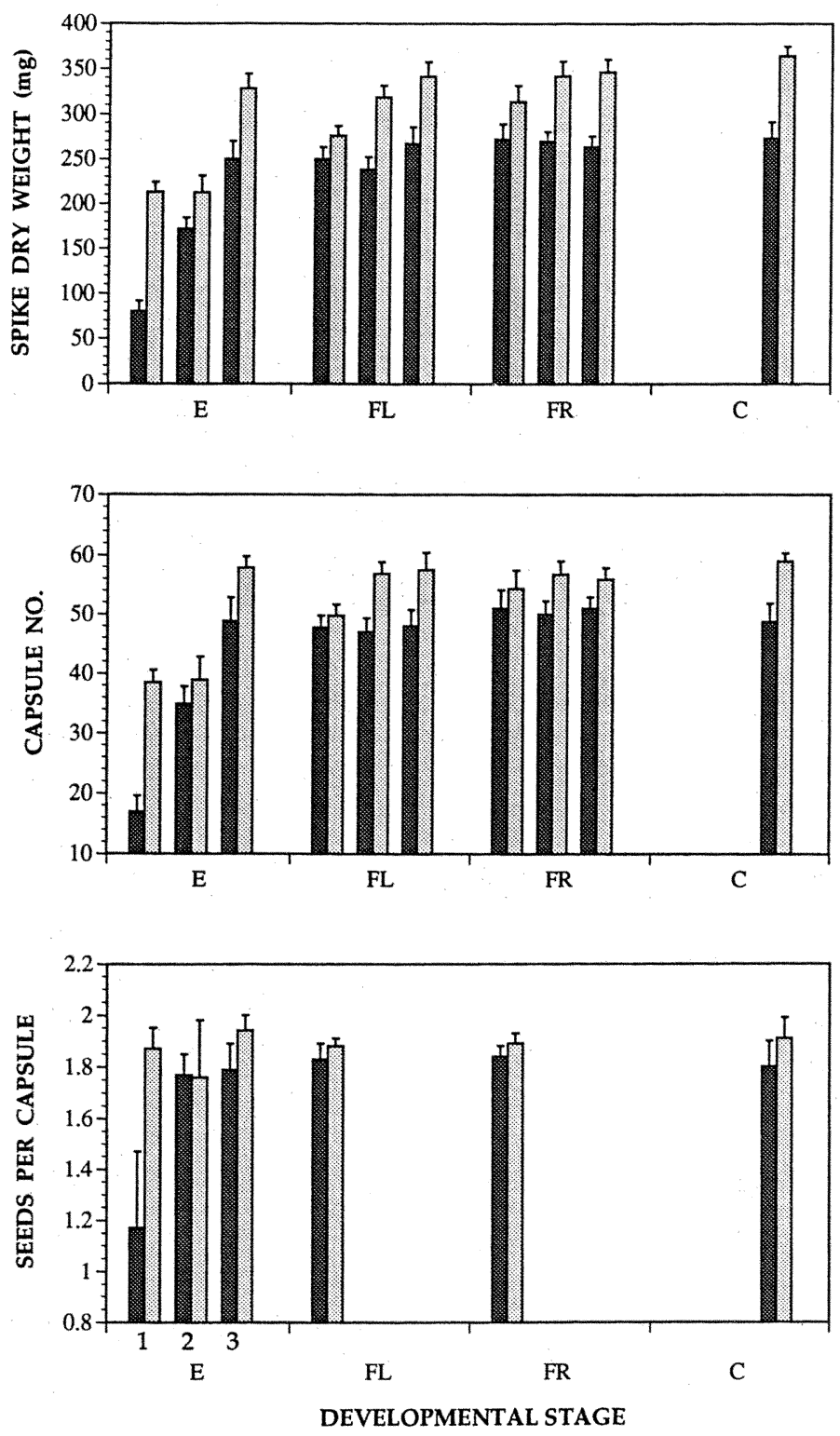

Fig. 2. Reproductive responses to defoliation at different developmental stages in Plantago aristata expressed in terms of mean $\pm 2 \mathrm{SE}$ shown by population. The two populations are identified by different amounts of shading. Graphs A-C refer to the response of the marked metamer in terms of: A) dry weight of the reproductive spike, B) capsule number, C) seeds per capsule. Developmental stages at time of removal: spike elongation (E), flowering $(\mathrm{Fl})$, fruiting $(\mathrm{Fr})$. Removal treatments: $1=$ bract and leaf removal, $2=$ bract removal, $3=$ leaf removal. No removals were made on the controls $(\mathrm{C})$.

weight strongly influence fitness, while a trait like spike length probably does not. Because the species is cleistogamous, it "need not" display its flowers to pollinators to effect seed set. Also, seeds typically fall close to the parent plant regardless of spike length. While defoliation during spike elongation reduced capsule number more than it did spike length, it reduced spike length more than it did seeds per capsule and seed weight. Spike dry weight was also greatly reduced, although seed weight and the weight of accessory reproductive structures are confounded in this measurement.
TABLE 3. ANOVA mean square (MS) values for percent of total assimilated radioactive carbon that moved into the marked spike. ${ }^{a}$

\begin{tabular}{lccc}
\hline \hline \multicolumn{1}{c}{ Source } & df & $\begin{array}{c}\text { Percent imported } \\
\text { into spike } \\
\text { MS }\end{array}$ & $\begin{array}{c}\text { Percent imported } \\
\text { into spike } \\
\text { (per mg spike } \\
\text { dry weight) } \\
\text { MS }\end{array}$ \\
\hline Removal Treatment (T) & 1 & $0.4926^{\text {ns }}$ & $0.0004^{\text {ns }}$ \\
Developmental Stage (D) & 1 & $0.5669^{\text {ns }}$ & $0.0071^{* * *}$ \\
T*D & 1 & $0.7285^{\text {ns }}$ & $0.00008^{\text {ns }}$ \\
Error & 8 & 0.6799 & 0.0002 \\
\hline a $* * * *=P<0.0001 ; * * *=P<0.001 ;$ & $* *=P<0.01 ; *=P<0.05 ;$ \\
ns $=P \geq 0.10$. &
\end{tabular}

The above assumptions about limited resources and allocation patterns also suggest that defoliation should reduce capsule number more than it should seed weight (e.g., Adams, 1967; Harper, Lovell, and Moore, 1970; Stephenson, 1981). Fruit abortion has been considered the most important stage of reproductive regulation because it is energetically efficient to abort young fruits (Bookman, 1983). Seed weight is thought to change little in response to stress because of its large contribution to offspring fitness. (However, Marshall, Levin, and Fowler [1986] have correctly noted that different habitats may select for different patterns of plasticity in reproductive components.) In $P$. aristata, defoliation did reduce capsule number more than it did seed weight. When we defoliated the metamers during spike elongation, capsule number was reduced by $27 \%$ and seed weight by only $5 \%$. Thus, seed weight was the more conservative reproductive character. The proportional reduction in number of seeds per capsule was also low (7\%). We did not include seeds per capsule in our a priori predictions about the differences in reproductive responses because $P$. aristata produces a maximum of only two seeds per capsule. Therefore we suspected that the proportional reduction in seeds per capsule would be low for this reason alone. We were, in fact, surprised that defoliation produced any significant reduction in seeds per capsule. Primack (1978) found no deviation from two seeds per capsule in the herbarium specimens that he examined.

Lee and Bazzaz (1980) noted that decline in seed weight relative to other reproductive components should depend on the time of defoliation. Our data provide good evidence for this. The negative effects of defoliation persisted into the flowering and fruiting phases only for seed weight. Therefore, if we had chosen to defoliate our experimental plants only at onset of flowering, or later, we would have erroneously concluded that seed size showed a greater response to defoliation. Agricultural studies have also shown that delaying the time of stress relative to floral and fruit development decreases the negative effect on fruit and seed number but increasingly depresses seed weight (e.g., Sharrow, 1990; Rajewski and Francis, 1991).

Reproductive structures have been shown to contribute an important percentage of the carbon needed for reproduction in many trees, shrubs, and herbaceous plant species (e.g., Flinn and Pate, 1970; Bazzaz and Carlson, 1979; Bazzaz, Carlson, and Harper, 1979; Watson and Casper, 1984; Heilmeier and Whale, 1987). In P. aristata, these reproductive structures are the bracts. In fact, the bracts 
play a larger role than does the subtending leaf in maintaining a local carbon balance within a reproductive spike. Bract removal alone reduced all components of reproduction, while removal of the subtending leaf alone reduced none. We do not believe that these results suggest that the leaf does not provide carbon for the spike. In another study of $P$. aristata, more than $70 \%$ of the radioactive carbon exported from a subtending leaf moved into its associated spike during spike elongation (Lacey and Marshall, 1992). Therefore, subtending leaves do translocate carbon to their associated spike. Rather, we hypothesize that bracts may be compensating for leaf removal by increasing their photosynthetic rate in response to changes in the source-sink balance of the metamer.

Our hypothesis is supported by the nonadditive effects of removing both bracts and subtending leaf. The removal of both bracts and leaf depressed reproduction more than we would have predicted from the independent effects of removing the bracts alone and the leaf alone (Fig. 1). When the bracts were missing, neither the rest of the metamer nor the rest of the shoot compensated for the loss of the leaf. Other studies have shown that after partial defoliation or shading, remaining leaves increase their photosynthetic rates per unit area (e.g., Stickler and Pauli, 1961; Thorne and Koller, 1974; Satoh, Kriedemann, and Loveys, 1977; Thomas and Stoddart, 1980; McNaughton, 1983; Yamashita and Fujino, 1986; Mendoza, Pinero, and Sarukhan, 1987; Gold and Caldwell, 1990). Our data suggest that the bracts, modified leaves, compensate for leaf removal by responding similarly.

It appears, however, that the importance of a subtending leaf as a direct carbon source for spike development varies among individual plants. In one population, the leaf contributed little to reproductive output, evidenced both by the observation that its removal, alone, did not depress output, when compared to the control and by the observation that its removal with bracts did not depress output below that observed when only bracts were removed (Fig. 2). In contrast, in the other population, the leaf did appear to contribute to reproductive output. Removal of both bracts and leaf depressed output below that observed when only bracts were removed. Thus, in the second population, bracts appeared to compensate for loss of a leaf, whereas in the first, they did not. Either the leaf contributed little to spike development or the rest of the metamer or shoot compensated for the loss.

There are two possible explanations for these interpopulational differences in response to defoliation. First, the differences might reflect environmentally induced parental effects. The effects of the maternal or paternal environment might have been carried over into the generation used for our experiment. Although environmentally induced parental effects have usually been detected only in seed traits, they sometimes persist into the adult, e,g., reproductive, phase of a life cycle (e.g., see reviews by Roach and Wulff, 1987; Lacey, 1990). Source-sink dynamics might be involved in these latter effects, but presently no studies address this issue. Alternatively, the populations may genetically differ in source-sink dynamics. If this latter explanation is correct, then it indicates the existence of the potential for evolutionary change in carbon integration patterns. Recent studies of grass species
(Welker et al., 1985; Wallace, 1990; Dyer et al., 1991) have detected interpopulational differences in the physiological responses to herbivory and artificial defoliation.

Our defoliation experiment shows that the removal of carbon sources within $P$. aristata produces a localized response. Defoliation reduced reproductive output within the defoliated metamer but not the total dry weight of other spikes on the plant. These data are consistent with Lacey and Marshall's (1992) study, which showed little carbon translocation among reproductive metamers in intact plants. The data are also consistent with the ${ }^{14} \mathrm{C}$ measurements made in this study, which showed that the amount of carbon moving from the shoot into marked metamers was small even when the metamer's leaf and bracts were removed. Thus, our initial assumption that a reproductive metamer is an IPU for carbon in $P$. aristata is supported.

Two other studies of carbon integration at the metameric level in naturally growing species permit a comparison with our data. Marquis (1988) observed a localized effect of defoliation in Acer pennsylvanicum. Removal of leaves directly subtending fruits reduced seed production in those fruits, while removal of neighboring leaves produced no effect. In contrast, Garrish and Lee (1989) observed that the number of fruits and seeds produced by defoliated vs. intact metamers did not differ significantly in Cassia fasciculata. Thus, at the metameric level, patterns of carbon integration, as measured in terms of its reproductive consequences, differ among species. Furthermore, the data show that integration among metamers is not correlated with the compactness of a species, as has been hypothesized by Schmid (1990) for clonal plants.

Our defoliation experiment was not performed to mimic herbivory in $P$. aristata. Rather it was performed to help learn more about carbon allocation patterns in the species. $P$. aristata is one of three annual species of Plantago indigenous to the southeastern United States. All three species can be found growing in frequently disturbed fields and roadsides; sometimes they have been found growing together (Lacey, personal observation). All indigenous species of Plantago germinate at approximately the same time; however, $P$. aristata survives longer and reproduces later in the growing season. In some summers it can persist through the summer to flower a second time (Primack, 1979). In contrast to $P$. virginica, one of the other two indigenous annuals, $P$. aristata shows little ${ }^{14} \mathrm{C}$ translocation among reproductive metamers in intact plants (Lacey and Marshall, 1992). Our data show that a metamer of $P$. aristata remains largely autonomous even after defoliation within the metamer. It is possible that this difference in pattern of carbon integration may contribute to the species' increased longevity. Carbon resources may not be drained away from other shoot metamers and the root to make up for lost resources in the damaged metamer.

Future defoliation studies should consider the effects of defoliation both at the whole plant level and at the level of the IPU. As Harper (1977) has compellingly argued, a plant is an assemblage of reiterated morphological units, each of which may have its own physiological program. Understanding how an individual plant interacts with its environment requires understanding not only how a whole plant responds to the environment but also how 
the units constituting the plant respond to the environment and to each other.

\section{LITERATURE CITED}

ADAMS, M. W. 1967. Basis of yield component compensation in crop plants with special reference to the field bean Phaseolus vulgaris. Crop Science 7: 505-510.

Agren, J. 1989. Seed size and number in Rubus chamaemorus: between-habitat variation, and effects of defoliation and supplemental pollination. Journal of Ecology 77: 1080-1092.

BAzZAZ, F. A., AND R. W. CARLSON. 1979. Photosynthetic contribution of flowers and seeds to reproductive effort of an annual colonizer. New Phytologist 82: 223-232.

- R. W. Carlson, and J. L. Harper. 1979. Contribution to reproductive effort by photosynthesis of flowers and fruits. Nature 279: 554-555.

- AND E. G. ReEKIE. 1985. The meaning and measurement of reproductive effort in plants. In J. White [ed.], Studies on plant demography: a FESTSCHRIFT for John L. Harper, 373-389. Academic Press, London.

BERTIN, R. I. 1982. The ecology of sex expression in red buckeye. Ecology 63: 445-456.

Bookman, S. S. 1983. Costs and benefits of flower abscission and fruit abortion in Asclepias speciosa. Ecology 64: 264-273.

Chapman, D. F., M. J. Robson, and R. W. Snaydon. 1992. Physiological integration in the clonal perennial herb Trifolium repens L. Oecologia 89: 338-347.

Dyer, M. I., M. A. Acra, G. M. Wang, D. C. Coleman, D. W. FreckMan, S. J. MCNaughton, AND B. R. Strain. 1991. Source-sink carbon relations in two Panicum coloratum ecotypes in response to herbivory. Ecology 72: 1472-1483.

FuinN, A. M., AND J. S. PATE. 1970. A quantitative study of carbon transfer from pod and subtending leaf to the ripening seed of the field pea (Pisum sativum L.). Journal of Experimental Botany 21: 71-82.

GARRISH, R. S., AND T. D. LEe. 1989. Physiological integration in Cassia fasciculata Michx.: inflorescence removal and defoliation experiments. Oecologia 81: 279-284.

Gold, W. G., AND M. M. CALDwEll. 1990. The effects of the spatial pattern of defoliation on regrowth of a tussock grass. III. Photosynthesis, canopy structure and light interception. Oecologia 82: $12-17$

HARPER, J. L. 1977. Population biology of plants. Academic Press, London.

, P. H. Lovell, AND K. G. Moore. 1970. The shapes and sizes of seeds. Annual Review of Ecology and Systematics 1: 327-356.

HeIlmeier, H., AND D. M. Whale. 1987. Carbon dioxide assimilation in the flowerhead of Arctium. Oecologia 73: 109-115.

Hutchings, M. J., AND I. K. BradBURY. 1986. Ecological perspectives on clonal perennial herbs. BioScience 36: 178-182.

JANZEN, D. H. 1976. Effect of defoliation on fruit-bearing branches of the Kentucky coffee tree, Gymnocladus dioicus (Leguminosae). American Midland Naturalist 95: 474-478.

Johnson, M. F. 1981. Phrymaceae and Plantaginaceae in Virginia. Virginia Journal of Science 32: 12-16.

Kemball, W. D., M. J. Palmer, And C. Marshall. 1992. The effect of local shading and darkening on branch growth, development and survival in Trifolium repens and Galium aparine. Oikos 63: 366375.

LACEY, E. P. 1990. Parental effects of life-history traits in plants. In E. C. Dudley [ed.], The unity of evolutionary biology, 735-744. Timber Press, Portland, OR.

- AND C. MARShall. 1992. Carbon integration in two Plantago species. American Journal of Botany 79: 1108-1112.

LANDA K., B. BenNer M. A. WAtson, AND J. Gartner. 1992. Physiological integration for carbon in mayapple (Podophyllum peltatum), a clonal herb. Oikos 63: 348-356.

LeE T. D., AND F. A. BAzZAZ. 1980. Effects of defoliation and competition on growth and reproduction in the annual plant Abutilon theophrasti. Journal of Ecology 68: 813-821.

Lloyd, D. G. 1980. Sexual strategies in plants. I. An hypothesis of serial adjustment of maternal investment during one reproductive session. New Phytologist 86: 69-79.

MARQUIS, R. J. 1988. Intra-crown variation in leaf herbivory and seed production in striped maple, Acer pensylvanicum L. (Aceraceae). Oecologia 77: 51-55.

MARSHALl, C. 1990. Source-sink relations of interconnected ramets. In $\mathrm{J}$. van Groenendael and $\mathrm{H}$. de Kroon [eds.], Clonal growth in plants: regulation and function. 32-41. SPB Academic, The Hague. -, AND M. A. WATSON. 1992. Ecological and physiological aspects of reproductive allocation. In C. Marshall and J. Grace [eds.], Fruit and seed production, 173-202. Cambridge University Press, Cambridge.

MARSHALl, D. L. 1989. Integration of response to defoliation within plants of two species of Sesbania. Functional Ecology 3: 207-214. , D. A. LeVIN, AND N. L. Fowler. 1986. Plasticity of yield components in response to stress in Sesbania macrocarpa and Sesbania vesicaria (Leguminosae). The American Naturalist 127: 508521.

McNaughton, S. J. 1983. Compensatory plant growth as a response to herbivory. Oikos 40: 329-336.

Mendoza A., D. Pinero, AND J. Sarukhan. 1987. Effects of experimental defoliation on growth, reproduction and survival of Astrocaryum mexicanum. Journal of Ecology 75: 545-554.

PitelkA, J. F., AND J. W. Ashmun. 1985. Physiology and integration of ramets in clonal plants. In J. B. C. Jackson, L. W. Buss, and R. E. Cook [eds.], Population biology and evolution of clonal organisms, 399-435. Yale University Press, New Haven, CT.

Primack, R. B. 1978. Regulation of seed yield in Plantago. Journal of Ecology 66: 835-847.

. 1979. Reproductive effort in annual and perennial species of Plantago (Plantaginaceae). The American Naturalist 114: 51-62.

RAJEWSKI, J. F., AND C. A. FranCIS. 1991. Defoliation effects on grain fill, stalk rot, and lodging of grain sorghum. Crop Science 31: 353359.

RoACH, D. A., AND R. WULFF. 1987. Maternal effects in plants: evidence and ecological and evolutionary significance. Annual Review of Ecology and Systematics 18: 209-235.

SAS InSTITUTE, INC. 1985. SAS user's guide: statistics. SAS Institute, Inc., Cary, NC.

Satoh, M., P. E. KriedemanN, AND B. R. Loveys. 1977. Changes in photosynthetic activity and related processes following decapitation in mulberry trees. Physiologia Plantarum 41: 203-210.

SCHMID, B. 1990. Some ecological and evolutionary consequences of modular organization and clonal growth in plants. Evolutionary Trends in Plants 4: 25-34.

SharRow, S. H. 1990. Defoliation effects on biomass yield components of winter wheat. Canadian Journal of Plant Science 70: 1191-1194.

Shea, M. M., AND M. A. WATson. 1989. Patterns of leaf and flower removal: their effect on fruit growth in Chamaenerion angustifolium (fireweed). American Journal of Botany 76: 884-890.

Stephenson, A. G. 1980. Fruit set, herbivory, fruit reduction and the fruiting strategy of Catalpa speciosa (Bignoniaceae). Ecology 61 $57-64$.

. 1981. Flower and fruit abortion: proximate causes and ultimate functions. Annual Reviews of Ecology and Systematics 12: 253-279. - 1984. The regulation of maternal investment in an indeterminant flowering plant (Lotus corniculatus). Ecology 65: 113-131.

Stickler, F. C., AND A. W. PAULI. 1961. Leaf removal in grain sorghum. I. Effects of certain defoliation treatments on yield and components of yield. Agronomy Journal 53: 99-102.

ThOMAS, H., AND L. StodDART. 1980. Leaf senescence. Annual Review of Plant Physiology 31: 83-111.

ThomAs, L. P., AND M. A. WATSON. 1988. Leaf removal and the apparent effects of architectural constraints on development in Capsicum annum. American Journal of Botany 75: 840-843.

ThorNe, J. H., AND H. R. Koller. 1974. Influence of assimilate demand on photosynthesis, diffusive resistances, translocation and carbohydrate levels of soybean leaves. Plant Physiology 54: 201207.

Tuomi, J., T. Vuorisalo, P. Niemela, E. Haukioja. 1989. Effects of defoliation on female inflorescences in mountain birch, Betula pubescens ssp. tortuosa. Canadian Journal of Botany 67: 334-338.

WALLACE, L. L. 1990. Comparative photosynthesis responses of big 
blue stem to clipping and grazing. Journal of Range Management 43: $58-61$.

WATSON, M. A. 1986. Integrated physiological units in plants. Trends in Ecology and Evolution 1: 119-123.

, AND B. B. CASPER. 1984. Morphogenetic constraints on patterns of carbon distribution in plants. Annual Review of Ecology and Systematics 5: 233-258.
Welker, J. M., E. J. RyKiel, D. D. Briske, AND J. D. GoesChl. 1985. Carbon import among vegetative tillers within two bunchgrasses: assessment with carbon-11 labelling. Oecologia 67: 209-212.

YAMASHITA, T., AND A. FuJiNo. 1986. Effects of pruning of young and old shoots on ribulose bisphosphate carboxylase and other constituents in leaves of the mulberry tree (Morus alba L.). Journal of Experimental Botany 37: 1836-1841. 